\title{
Incorporation of surface plasmon resonance with novel valinomycin doped chitosan- graphene oxide thin film for sensing potassium ion
}

\begin{abstract}
ABSTRCT
In this study, the combination of novel valinomycin doped chitosan-graphene oxide (C-GO$\mathrm{V})$ thin film and surface plasmon resonance (SPR) system for potassium ion $\left(\mathrm{K}^{+}\right)$detection has been developed. The novel $\mathrm{C}-\mathrm{GO}-\mathrm{V}$ thin film was deposited on the gold surface using spin coating technique. The system was used to monitor SPR signal for $\mathrm{K}^{+}$in solution with and without $\mathrm{C}-\mathrm{GO}-\mathrm{V}$ thin film. The $\mathrm{K}^{+}$can be detected by measuring the SPR signal when $\mathrm{C}-\mathrm{GO}-\mathrm{V}$ thin film is exposed to $\mathrm{K}^{+}$in solution. The sensor produces a linear response for $\mathrm{K}^{+}$ ion up to $100 \mathrm{ppm}$ with sensitivity and detection limit of $0.00948^{\circ} \mathrm{ppm}^{-\mathrm{I}}$ and $0.001 \mathrm{ppm}$, respectively. These results indicate that the $\mathrm{C}-\mathrm{GO}-\mathrm{V}$ film is high potential as a sensor element for $\mathrm{K}^{+}$that has been proved by the SPR measurement.
\end{abstract}

Keyword: Surface plasmon resonance; Chitosan; Graphene oxide; Valinomycin; Potassium ion. 